\title{
Importance of projects for public health institutes in transitional countries: case of the public health institute of republika srpska
}

\begin{abstract}
Like many public healthcare facilities in South-Eastern Europe, the Public Health Institute of Republika Srpska (PHI RS) has recently faced the problem of irregular inflow of funds from the state budget and health insurance fund and had to seek for additional sources of funding. The objective of this paper is to assess the importance of projects for operation of the public health institutes in transitional countries where multiple donors are active, based on the PHI RS's case. The RS PHI has recently assumed five different roles during projects. In the role of the final project beneficiary, the RS PHI was one of the target organizations who were to benefit from premises renovation, equipment delivery, strengthening of staff capacities, exchange of experience and practices through study visits, improvement of legal environment or advancing its position in the health system. As the project partner, the PHI RS has used its unique position in the health system to attract project funding. The PHI RS has as contractor provided its services under different projects. Occasionally, the PHI RS has been the resource center that provided experts needed for implementation of the projects. It promoted the PHI RS's expertise and helped the PHI RS to retain and reward its most qualified staff. Potentially the most beneficial role for the PHI RS is the one of the main applicant for projects. All other roles have supported building of the PHI RS's capacity to take the role of the lead applicant in different types of projects. In transitional countries where donors do not pool their funds, the public health institutes have a chance to exploit availability of multiple sources of financing and to benefit from parallel participation in different projects.
\end{abstract}

Volume I Issue I - 2014

\author{
Severin Rakic,' Slobodan Stanic ${ }^{2}$ \\ 'Center for Health Management, Public Health Institute of \\ Republika Srpska, Bosnia and Herzegovina \\ ${ }^{2}$ Public Health Institute of Republika Srpska, Bosnia and \\ Herzegovina
}

Correspondence: Severin Rakic, Center for Health Management, Public Health Institute of Republika Srpska, Jovana Ducica I, 78000 Banja luka, Bosnia and Herzegovina, Tel +387 65 927 531, Fax +38751 216510, Email severinrakic@teol.net

Received: October 20, 2014 | Published: November 28,2014

Keywords: project, public health institute

Abbreviations: AIDS, acquired immune deficiency syndrome; DOTS, directly observed treatment, short-course; HIV, human immunodeficiency virus; PHI, public health institute; PHI RS, public health institute of republika srpska; UNDP $\mathrm{BiH}$, united nations development programme in bosnia and herzegovina

\section{Introduction}

Public spending on health fell or slowed in many European countries between 2007 and 2012, both as a share of government spending and in absolute terms. ${ }^{1}$ A significant number of the public healthcare facilities in South-Eastern Europe has consequently faced the problem of irregular inflow of funds from the state budget and health insurance funds and had to seek for additional sources of funding. The Public Health Institute of Republika Srpska (PHI RS) has been one of such facilities, which, among other sources, has relied on project-based financing.

The Republika Srpska is one of two entities in Bosnia and Herzegovina (the other being the Federation of Bosnia and Herzegovina), which has its own legislative and executive functions and responsibilities, including those related to healthcare. It has population of about 1.3 million. Government of its health system is centralized, with planning, regulation and management functions held by the Ministry of Health and Social Welfare.

There are no recent reliable data on level of development assistance at country level. Based on the latest information, members of the Donor Coordination Forum have allocated 541million EUR to Bosnia and Herzegovina in $2011 .^{2}$ In comparison to the previous period, grantbased development assistance showed a significant decline. Largest share of the development assistance was provided to the infrastructure sector, economic development, social protection and health sector. The investments in the health sector were about 61million EUR in 2011, out of which grant-based financing was about 8.5million EUR. The leading donors in the health sector were European Investment Bank, The World Bank, Swiss Agency for Development and Cooperation, World Health Organization, United Nations Population Fund, International Organization for Migration, Global Fund to Fight AIDS, Tuberculosis and Malaria, Global Alliance for Vaccines and Immunization, Swiss State Secretariat for Economic Affairs, United Nations Children's Fund, Italian Cooperation and European Union/European Commission. Majority of the donors provided their financing in a form of projects or programs support.

The objective of the paper is to assess the importance of projects for operation of the public health institutes in transitional countries where multiple donors are active, based on the PHI RS's case. Results of such review can prove to be useful to public health institutes (PHIs) in other transitional countries.

\section{Conclusion}

The PHI RS works under direct jurisdiction of the Ministry of Health and Social Welfare, but it also partially operates under the local commercial laws. In recent years, about $30 \%$ of the PHI RS's annual revenues have come from public funding (budget and health 
insurance), while about $70 \%$ of the revenues have come from different commercial contracts and project related funding. Average share of project related financing in total revenues of the PHI RS was about $17 \%$ in period 2011-2013 (Figure 1).

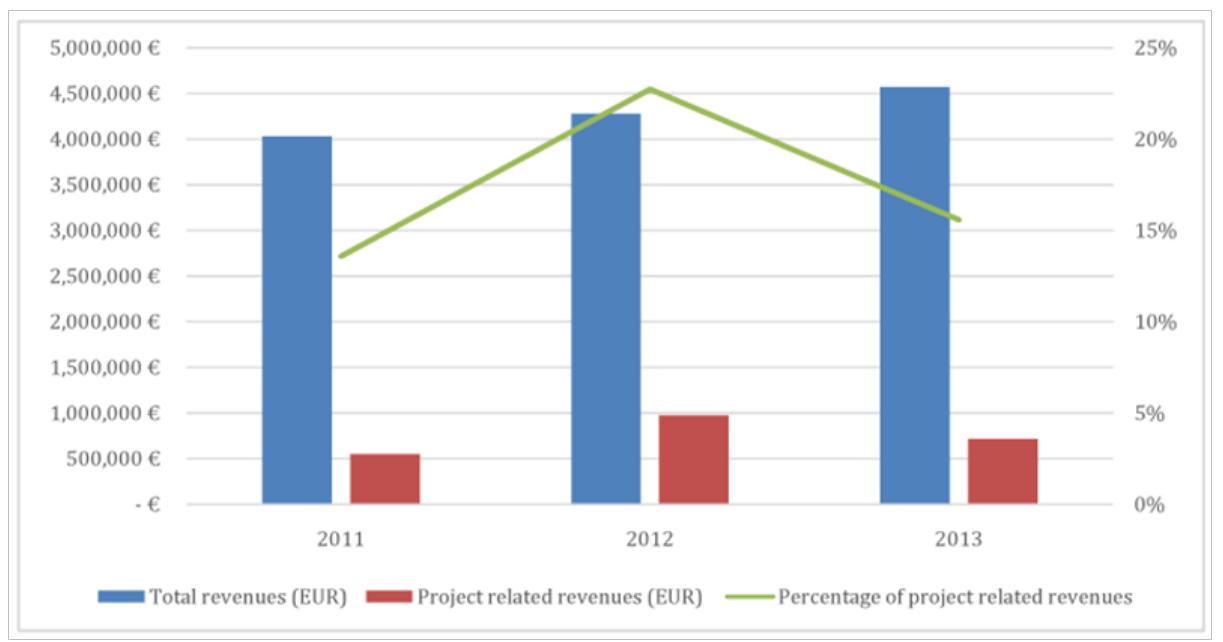

Figure I Percentage of project related revenues of the Public Health Institute of Republika Srpska in period 20I I-20I3.

The project related revenues comprised of direct inflow of money to the PHI RS (based on the grant and project agreements) and project investments in civil works, equipment and supplies for the PHI RS. These revenues have participated significantly in the total revenues of the PHI RS. This has resulted from the extensive efforts of the PHI RS's top management to raise the share of the project related revenues. The approach taken by the top management was that the PHI RS should take any available opportunity to participate in the projects, in order to strengthen its position and increase chances of getting valuable projects in the future. There have been five different roles that the PHI RS has assumed during projects over the last five years - project beneficiary, project partner, contractor, resource center and applicant.

The role of the final project beneficiary meant that the PHI RS was one of the target organizations who were to benefit from the project in the long term. The benefits could be of a different nature: premises renovation, equipment delivery, strengthening of staff capacities, exchange of experience and practices through study visits, improvement of legal environment for PHI RS's functioning, advancing Institute's position or developing new Institute's functions in the health system. For example, the PHI RS's microbiological laboratory was renovated and additional equipment for the laboratory was supplied in 2014, under the project strengthening of DOTS Strategy and Improving National Tuberculosis Program, Including Multidrug Resistant and Infection Control, in Bosnia and Herzegovina. ${ }^{3}$ The total value of the investment was about 525.000 EUR.

The PHI RS was also among project beneficiaries of two European Union financed projects. The project Strengthening of Public Health Institutes in Bosnia and Herzegovina, implemented in period 20092011, aimed to strengthen the capacity of the public health functions at all levels, with special focus on public health as an integrated part of planning and decision making process and fulfillment of international obligations, as well as to contribute to reform of the public health system through support to implementation of existing health promotion programs and improvement of national preparedness to public health needs and the systems for health monitoring and disease surveillance. ${ }^{4}$ The project Public Health Reform II in Bosnia and Herzegovina, implemented in period 2012-2013, aimed to support health care reforms through harmonization of public health legislation with the European Union directives and regulations, in order to enhance evidence based planning of health care system. ${ }^{5}$ The PHI RS had certain benefits from the technical assistance provided under both of the projects. There were, however, difficulties related to use of the technical assistance, available under the projects. These difficulties, which reduced effectiveness of the projects, originated from the project preparation phase. Due to the complex administrative structure of Bosnia and Herzegovina, during the preparation phases the needs of PHI RS were assessed and terms of references for the projects were developed without sufficient participation of the PHI RS's staff.

As the project partner, the PHI RS has used its unique position in the health system to attract project funding. Where involvement of the Institute in the projects were considered to be of critical importance for success of activities, the PHI RS has readily accepted invitations from the main implementation agencies for participation in the projects in the role of project partner. This was the case with a number of smaller projects, but also with two larger projects financed by the grants from the Global Fund to Fight AIDS, Tuberculosis and Malaria. As the main implementing agency, the United Nations Development Program in Bosnia and Herzegovina (UNDP $\mathrm{BiH}$ ) remained fully responsible for implementation of the Global Fund's grants. The PHI RS was selected for one of the sub-recipients, to which the UNDP BiH provided funding in order to carry out activities contemplated under the projects Strengthening of DOTS Strategy and Improving National Tuberculosis Program, Including Multidrug Resistant and Infection Control, in Bosnia and Herzegovina ${ }^{3}$ and Scaling up Universal Access for Most at Risk Populations in Bosnia and Herzegovina (HIV/AIDS Round 9). ${ }^{6}$ A substantial share of the PHI RS's project related funding in recent years can be attributed to these two projects.

The contractor, which provided its services under the project, was the third role for the PHIRS. For example, the line ministry contracted the PHI RS in 2012, under the World Bank's financed Health 
Sector Enhancement Project, to provide about 500 days of health management training over the three years period. ${ }^{7}$ The contract for the services was awarded to the PHI RS through a public procurement procedure. As lead implementing agency, the Ministry of Health and Social Welfare of Republika Srpska kept overall responsibility for the project coordination and implementation. As provider of the services, the PHI RS was responsible for preparation, organization and delivery of the training programs. The training participants and content of the training were selected by the Ministry. Availability of such longer term project financing enabled the PHI RS to establish the Health Management Centre as its new organizational unit. Such Institute's development activity would be impossible without initial financing provided under the project.

Occasionally, the PHI RS has been the resource center that provided experts needed for implementation of the projects. For example, about 20 employees of the PHI RS participated in conduction of the household survey on health status, health needs and utilization of health services, conducted in 2010 by a specialized consulting firm and financed by the line ministry under the Health Sector Enhancement Project. ${ }^{8}$ The PHI RS staff participated in the project as individual experts (e.g. methodology experts, researchers and data entry clerks). Though its staff directly financially benefited from such participation in the project, no direct financial benefits were incurred by the PHI RS. The underpinning thinking for allowing and facilitating such individual participation of the PHI RS's staff was that it allowed for strengthening of staff capacities and personal qualifications, which were both necessary for gaining access to future projects. Additionally, such participation of its staff has promoted the PHI RS's expertise, helped the Institute to retain the most qualified staff and provided opportunities to reward the persons whose regular wages were limited by the regulations.

Potentially the most beneficial role for the PHI RS is the one of the main applicant for projects. This is also the most demanding role, which requires existence of sufficient technical, financial and logistical capacities in the PHI RS. It involves active searching for possible sources of project funding, continuous building of relationships with donors and potential donors, timely acquiring of information on forthcoming calls for proposals, identification of potential partners, joint preparation of project concept notes and proposals with selected partners, direct signing of grant agreements with donors and taking over the full responsibility for successfully achieving project results. The PHI RS has been to some extent successful in this role. It succeeded in getting smaller local grants for research projects (e.g. examination of quality and health safety of honey and other bee products, supported by the Ministry of Agriculture, Forestry and Water Management of the Republika Srpska), international grants for research projects (e.g. investigation on use of drugs, tobacco and alcohol among secondary school students, supported by the European Monitoring Centre for Drugs and Drug Addiction) ${ }^{9}$ or local grants for implementation projects (e.g. implementation of action plan for solving Roma's healthcare related problems, supported by the Ministry of Human Rights and Refugees of Bosnia and Herzegovina), but no significant international grant has yet been awarded to the PHI RS for implementation of a development project in public health area. All the previously described roles have served important additional purpose: building PHI RS's capacity to successfully take the role of the lead applicant in different types of projects. This remains to be a way forward to the PHI RS.
Based on the PHI RS example, it can be concluded that there is a wide scope of reasons for the public health institutes to participate in projects. Research, development and implementation projects are all of importance to the PHIs. Projects are of particularly importance for financing PHI's development activities, which are difficult to fund from other sources. The importance of projects for PHIs in transitional countries is clearly evident in the time of economic crisis. In countries where donors do not pool their funds, the PHIs have a chance to exploit availability of multiple sources of financing and to benefit from parallel participation in different projects. The capacities, needed for a PHI to be lead applicant in larger internationally financed projects, cannot be built quickly. The PHIs experience with other roles in the projects is beneficial in building such capacities. This cannot be achieved without PHI's top management's understanding of the capacity building process and their active support in the process.

\section{Acknowledgements}

None.

\section{Conflict of interest}

The author declares no conflict of interest.

\section{References}

1. Thomson S, Figueras J, Evetovits T, et al. Economic crisis, health systems and health in Europe: impact and implications for policy. Policy summary 12. WHO Regional Office for Europe; 2014.

2. Ministry of Finance and Treasury of Bosnia and Herzegovina. Donor Mapping Report 2011-2012. Herzegovina: Donor Coordination Forum; 2013.

3. United Nations Development Programme. Strengthening of DOTS Strategy and Improving National Tuberculosis Program (NTP), Including Multidrug Resistant and Infection Control, in Bosnia and Herzegovina (BiH). Herzegovina: United Nations Development Programme in Bosnia and Herzegovina; 2014.

4. EPOS Health Management. Germany: Strengthening Public Health institutes in Bosnia and Herzegovina, Bad Homburg; 2011.

5. CEU Consulting/DIADIKASIA S.A. Consultants. Progress report \#2. Annex 6-Revised project Terms of Reference, Public Health Reform II. Bosnia and Herzegovina; 2012.

6. United Nations Development Programme. Scaling up Universal Access for Most at Risk Populations in Bosnia and Herzegovina (HIV/AIDS Round 9). Herzegovina: United Nations Development Programme in Bosnia and Herzegovina; 2014.

7. Public Health Institute of Republika Srpska. Inception report for assignment "Provision of services for health management training". Ministry of Health and Social Welfare. Herzegovina: Public Health Institute; 2012.

8. Ministry of Health and Social Welfare and Public Health Institute of Republika Srpska. Research on Health Status of Republika Srpska's Population. Herzegovina: Public Health Institute; 2011.

9. Siljak S, Stojisavljevic D, Niskanovic J. European investigation on use of drugs, tobacco and alcohol among secondary school students: Report for Republika Srpska. Public Health Institute of Republic Srpska; 2008. 